\title{
A Phase I Trial and in vitro Studies Combining ABT-751 with Carboplatin in Previously Treated Non-Small Cell Lung Cancer Patients
}

\author{
Tian Ma ${ }^{\mathrm{a}}$ Alexander D. Fuld ${ }^{\mathrm{b}}$ James R. Rigas ${ }^{\mathrm{b}-\mathrm{d}}$ Anne E. Hagey \\ Gary B. Gordon ${ }^{\text {e Ethan Dmitrovsky }}{ }^{\text {a-d }}$ Konstantin H. Dragneveved \\ Departments of a Pharmacology and Toxicology and ${ }^{b}$ Medicine, and c Norris Cotton Cancer Center, \\ Dartmouth Medical School, Hanover, N.H., ${ }^{d}$ Dartmouth-Hitchcock Medical Center, Lebanon, N.H., and \\ eAbbott Laboratories, Abbott Park, III., USA
}

\section{Key Words}

ABT-751 • Carboplatin • Phase I clinical trial $\cdot$ Non-small cell lung cancer

\begin{abstract}
Background: ABT-751 is a novel antimitotic agent that exerted cytotoxic effects in preclinical studies. Carboplatin has efficacy in treating advanced non-small cell lung cancer (NSCLC) in combination with other drugs. Methods: Lung cancer cell lines were treated with ABT-751 and/or carboplatin to investigate their impact on cell growth. A phase I study with an expansion cohort was conducted in previously treated NSCLC patients. The primary objective was the maximum tolerated dose (MTD); secondary objectives were objective response rates, median survival, time to tumor progression, dose-limiting toxicities (DLTs), and pharmacodynamic evaluation of buccal swabs. Results: Combining ABT-751 with carboplatin significantly reduced growth and induced apoptosis of lung cancer cell lines. Twenty advanced NSCLC patients were enrolled. MTD was ABT-751 $125 \mathrm{mg}$ orally twice daily for 7 days with carboplatin AUC 6. DLTs included fatigue, ileus, neutropenia and pneumonitis. Two patients had confirmed partial responses. Median overall survival was 11.7 months (95\% Cl 5.9-27.0). Time to tumor progression was 2.8 months
\end{abstract}

(95\% Cl 2.0-2.7). Four of 6 patients showed decreased cyclin D1 protein in posttreatment versus pretreatment buccal swabs. Conclusion: Combining ABT-751 with carboplatin suppressed growth of lung cancer cell lines and had modest clinical antitumor activity in advanced NSCLC previously treated predominantly with carboplatin. Further studies of this combination are not recommended while investigations of biomarkers in different patient populations, alternative schedules and combinations may be pursued.

Copyright $\odot 2012$ S. Karger AG, Basel

\section{Introduction}

Lung cancer is the leading cause of cancer death globally and in the United States [1]. Improved outcomes in the treatment of advanced stages of lung cancer may be observed with combination chemotherapy regimens. Agents that act at different phases or inhibit specific components of the cell cycle are often combined. This can enhance antineoplastic activity of the regimen as compared to the antitumor effects of each agent used in the regimen. Two-drug platinum-based combinations have emerged as a standard treatment option for patients with advanced non-small cell lung cancer (NSCLC) [2-4].

\section{KARGER}

Fax +4161306 1234 E-Mail karger@karger.ch www.karger.com

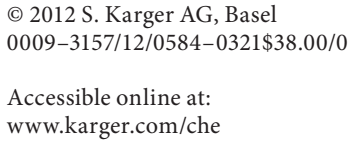

Konstantin H. Dragnev, MD

Dartmouth-Hitchcock Medical Center

1 Medical Center Drive

Lebanon, NH 03756 (USA)

E-Mail konstantin.h.dragnev@hitchcock.org 
Carboplatin or cisplatin combined with a microtubuleinterfering drug (paclitaxel, docetaxel or vinorelbine) or with an antimetabolite (gemcitabine, pemetrexed) were compared in several large randomized trials conducted in the United States and worldwide [5-8]. These studies demonstrated similar response rates, overall and 1-year survival with minor differences in toxicities. Unfortunately, all patients with advanced NSCLC relapse [9]. Once this occurs, median survival is typically between 4 and 8 months [10-13].

The US FDA has approved three drugs (pemetrexed, docetaxel and erlotinib) for use in second-line treatment of NSCLC. While these agents have different mechanisms of action and toxicities, the benefits are similar, with response rates of $8 \%$ and median survival in randomized studies improving to 8 months [14]. More effective treatments are needed for relapsed NSCLC.

Microtubules are a target of multiple chemotherapy agents including vinca alkaloids and taxanes. By binding to tubulin and disrupting microtubule dynamics, these agents block the cell cycle at the $\mathrm{G}_{2} / \mathrm{M}$ phase and induce apoptosis. However, the efficacy of these agents is limited by the development of resistance [15]. ABT-751 (previously known as E7010) is a novel oral sulfonamide [16] that binds the colchicine-binding site of $\beta$-tubulin, thereby inhibiting microtubule polymerization and leading to $\mathrm{G}_{2} / \mathrm{M}$ arrest [17]. In addition to its cytotoxic effects, ABT751 also demonstrated vascular disrupting effects by decreasing tumor perfusion in animal studies $[18,19]$. Preclinical studies of ABT-751 showed antitumor activity against multiple rodent tumor cell lines and in xenograft models of human tumors, including gastric, colon, breast and lung cancer $[20,21]$. Notably, ABT-751 is not a multidrug resistance transporter substrate and shows activity in cell lines that are resistant to taxanes and vinca alkaloids $[17,22]$.

Five phase I studies of ABT-751 have been performed in pediatric and adult patients with advanced malignancies [23-27]. Study results support fixed dosing (i.e. nonbody surface area-based dosing) [25] and suggest that divided-dose scheduling best maintained blood levels of the drug [26]. The recommended phase II dose schedule was $150 \mathrm{mg}$ orally twice daily given for 7 days every 3 weeks [25].

ABT-751 is well tolerated; dose-limiting toxicities (DLTs) in the adult population are peripheral neuropathy and ileus [23-27]. A phase IB study of ABT-751 and docetaxel in patients with castration-resistant prostate cancer had DLTs of febrile neutropenia, diarrhea and nausea [28]. Interestingly, ABT-751 demonstrated limited myelosuppression, thus it may be safely combined with myelosuppressing chemotherapies [23-25].

Preclinical studies of ABT-751 in combination with other cytotoxic therapies in xenograft models of NSCLC and colon cancer have shown additive or greater cooperativity [29]. In the Calu-6 lung cancer model, ABT-751 in combination with cisplatin exhibited greater than additive responses for all three studied doses of ABT-751 tested (Abbott, data on file). In clinical practice in the United States, carboplatin has become a standard drug for combination therapy for advanced NSCLC. Moreover, it has a more favorable toxicity profile than cisplatin [30, 31].

Based on their antitumor activity and their favorable toxicity profile, we proposed that the combination of ABT-751 and carboplatin might prove effective in treating advanced NSCLC patients. Therefore, we conducted a phase I trial with an expansion cohort of the combination of ABT-751 and carboplatin in previously treated patients with advanced NSCLC. The primary objective was to evaluate the maximum tolerated dose (MTD) of escalating doses of ABT-751 when used in combination with carboplatin. Secondary endpoints were objective response rates after two cycles of treatment, median survival, time to tumor progression, DLTs and side-effect profile, along with pharmacodynamic evaluations.

\section{Patients and Methods}

Cell Culture, Proliferation, Apoptosis and Immunoblot Assays

Human lung cancer cell lines HOP62, A549 and U1517 were each cultured in RPMI-1640 medium supplemented with $10 \%$ fetal bovine serum, $100 \mathrm{U} / \mathrm{ml}$ penicillin and streptomycin at $37^{\circ} \mathrm{C}$ with $5 \% \mathrm{CO}_{2}$ in a humidified incubator. ABT-751 (Abbott, Abbott Park, Ill., USA) was dissolved in dimethylsulfoxide and carboplatin (Sigma-Aldrich, St. Louis, Mo., USA) was dissolved in water. For proliferation assays, HOP62, A549 and U1517 cells were independently seeded at $4 \times 10^{3}$ per well in 6 -well culture plates and treated with the indicated drugs $24 \mathrm{~h}$ later. Experiments were done in triplicates and results were replicated in independent experiments. Logarithmically growing cells were assayed $72 \mathrm{~h}$ following drug treatment using the CellTiter-Glo growth assay (Promega, Madison, Wisc., USA) according to previously established methods [32]. For apoptosis and immunoblot assays, HOP62 and A549 were independently treated with vehicle alone, ABT-751 alone, carboplatin alone or the combination of these drugs. Apoptosis was measured by the Annexin V-FITC signal by flow cytometry using the Annexin V:FITC Assay Kit (AbD Serotec, Raleigh, N.C., USA) according to the manufacturer's protocol. For immunoblot assays, cell lysates were harvested $72 \mathrm{~h}$ after the indicated drug treatments and subjected to individual immunoblot analysis as previously described [33] using an antibody against cyclin B1 (H-433, Santa Cruz Biotechnology, Santa Cruz, Calif., USA), cyclin D1 (M-20, Santa Cruz Biotechnology) or actin (C-11, Santa Cruz Biotechnology). 


\section{Patients}

Adult patients (age $>18$ ) with histologically confirmed diagnosis of advanced stage NSCLC (IIIB with malignant pleural effusion or stage IV) with at least one, but not more than two prior chemotherapy regimens were eligible for enrollment if there were at least one measurable lesion for Response Evaluation Criteria in Solid Tumors (RECIST) tumor assessments and they had adequate hematologic, renal and hepatic function, with a Karnofsky Performance Score of 70-90. Prior treatment with a platinum agent was allowed. Exclusion criteria included untreated central nervous system metastases, neuropathy, gastrointestinal abnormalities, concurrent colchicine therapy, and cytotoxic chemotherapy within 3 weeks of initiating the investigational treatment. The protocol was approved by the Institutional Review Board at Dartmouth College. Voluntary written informed consent was obtained prior to any screening or study-specific procedures. The trial was registered on the ClinicalTrials.gov website as NCT00735878.

\section{Treatment and Dose Escalation}

ABT-751 was supplied as 25- and 100-mg capsules by Abbott Laboratories. To maximize the clinical tolerability of combining carboplatin with ABT-751, a twice-daily regimen for 7 out of 21 days was chosen. The carboplatin dose was given on day 4 of the first cycle to allow for a detailed pharmacodynamic assessment, and on day 1 of subsequent cycles. All cycles were 21 days. For the phase I portion of the study, a dose escalation trial design was chosen based on prior phase I data using the rapid dose escalation model (table 1) [34]. Cohorts of 1 patient each for the first 3 dose levels were treated. If a patient completed the first cycle without experiencing grade 2 toxicity, then enrollment at the next dose level commenced. If the patient experienced grade 2 toxicity or higher, then 2 additional patients were enrolled at the same dose level. At dose level 4, a minimum of 3 patients was to be enrolled. If 1 of the 3 patients experienced a grade 3 or higher toxicity, the cohort was to be expanded to 6 patients. However, if 3 patients completed one cycle at the assigned dose without experiencing a grade 3 or higher toxicity, then the next cohort would begin treatment. Once the MTD was established, that dose level was planned to be expanded with an additional 10 patients to assess efficacy and potential toxicities.

\section{Toxicities and Definition of MTD and DLTs}

Toxicities were defined by the National Cancer Institute Common Toxicity Criteria version 3.0 [35]. MTD was defined as the highest dose of ABT-751 given in combination with carboplatin at which less than one third of patients experienced a DLT at the end of the first cycle. DLTs were defined as an episode of febrile neutropenia (grade 4 neutropenia $(<500 / \mu \mathrm{l})$ lasting more than 6 days or any episode of febrile neutropenia or neutropenia with documented infection or sepsis), grade 3 or higher thrombocytopenia $(<50,000 / \mu l)$ that occurred on the day of scheduled treatment, grade 3 or higher nonhematologic toxicity (except nausea/ vomiting or anaphylactoid reactions) or inability to begin the next cycle of therapy within 2 weeks of its scheduled start due to delayed recovery. Any nonreversible toxicity greater than grade 2 was considered a DLT.

Patients had assessments for treatment-related toxicity on days 1,4 and 8 of the first cycle and at the start of each subsequent cycle. Tumor assessments were performed every two cycles. Dis-
Table 1. Dose escalation scheme

\begin{tabular}{lllll}
\hline Dose level (cohort) & $\begin{array}{l}\text { ABT-751 } \\
\text { mg b.i.d. } \\
\left(\text { not mg/m } \text { 2 }^{2}\right)\end{array}$ & $\begin{array}{l}\text { Carbo- } \\
\text { platin } \\
\text { AUC }\end{array}$ & $\begin{array}{l}\text { Planned } \\
\text { enrollment }\end{array}$ & $\begin{array}{l}\text { Enrolled } \\
\text { patients }\end{array}$ \\
\hline 1 & 100 & 4.5 & $1-6$ & 1 \\
2 & 125 & 4.5 & $1-6$ & 1 \\
$3^{\mathrm{a}}$ & 125 & 6 & $1-6$ & 5 \\
4 & 150 & 6 & $3-6$ & 5 \\
5 & 175 & 6 & $3-6$ & 0 \\
6 & 200 & 6 & $3-6$ & 0 \\
Expansion cohort & MTD & MTD & 10 & 7 \\
\hline
\end{tabular}

a After DLTs were identified at dose level 4, an additional 4 patients were enrolled at the level 3 dose (patients 10-13).

ease progression was determined using RECIST [36]. Survival information was gathered at 3-month intervals after the last study visit.

\section{Pharmacodynamic Studies}

Six patients treated at the MTD underwent pharmacodynamic analysis with buccal mucosa swabs on day 0 (before treatment) and days 4,8 , and 22 of treatment. The studied swabs were analyzed for cyclin B1 and cyclin D1 protein expression by immunoblot analysis, as previously described [33]. Immunoblot analyses were conducted with densitometry to determine cyclin B1 and cyclin D1 levels relative to actin expression as a loading control and as a confirmation of protein integrity.

\section{Statistical Methods}

For in vitro cancer cell line studies, changes in growth were evaluated by two-sample two-tailed t-test using Microsoft Excel software, and the comparison among the growth-suppressive effect of etoposide, gemcitabine and carboplatin was evaluated by one-way ANOVA using Graphpad Prism. $p<0.05$ was considered statistically significant. For the clinical trial, analyses of baseline patient characteristics, efficacy and safety were performed for all patients. Response rates along with confidence intervals were determined. Median and progression-free survival were determined using the Kaplan-Meier method as before [33].

\section{Results}

\section{Effects of Combining ABT-751 with Carboplatin in Lung Cancer Cell Lines}

A549 and HOP62 lung cancer cell lines were independently examined for growth-inhibitory responses after 3 days of treatment at drug dosages that were at the highest relative peak plasma values observed in prior clinical trials for etoposide $(8.6 \mu \mathrm{g} / \mathrm{ml})$, gemcitabine $(114 \mu \mathrm{M})$ and carboplatin $(39 \mu \mathrm{g} / \mathrm{ml})$ [37-39]. While growth of each cell 
Fig. 1. Effects of ABT-751 and carboplatin on cell growth in the indicated human lung cancer cell lines. Effects of individual and combined treatments of ABT-751 and carboplatin at the indicated dosages for 3 days on cell growth of human lung cancer cell lines HOP62, A549 and U1571. * $\mathrm{p}<$ 0.05 and $^{* *} \mathrm{p}<0.01$, respectively.

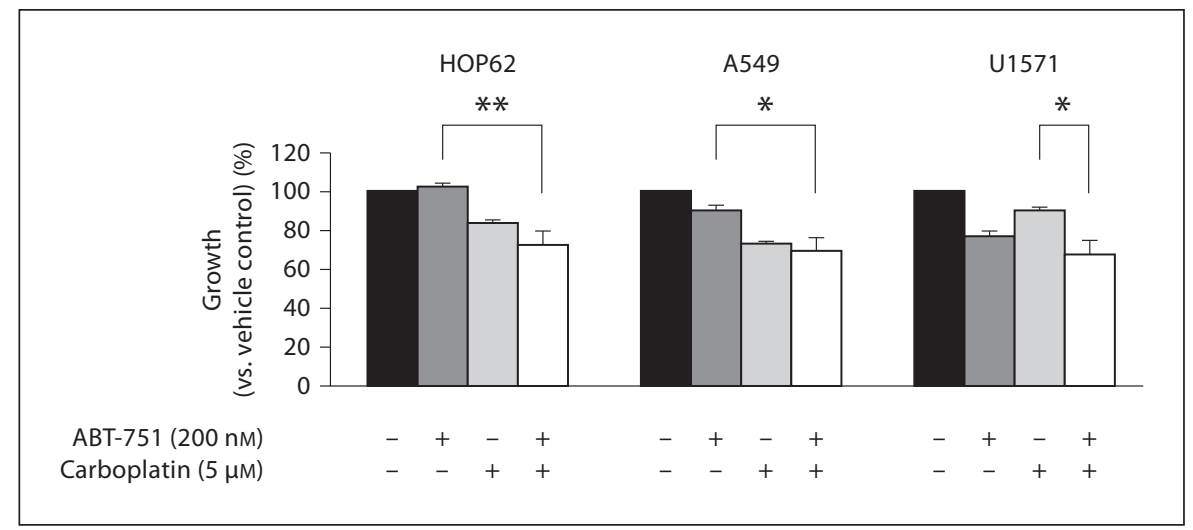

Table 2. Patient characteristics $(n=20)$

\begin{tabular}{|c|c|}
\hline Characteristic & \\
\hline \multicolumn{2}{|l|}{ Age, years } \\
\hline Median & 64 \\
\hline Range & $47-73$ \\
\hline \multicolumn{2}{|l|}{ Gender } \\
\hline Male & $13(65 \%)$ \\
\hline Female & $7(35 \%)$ \\
\hline \multicolumn{2}{|l|}{ Race } \\
\hline White & $20(100 \%)$ \\
\hline \multicolumn{2}{|l|}{ Stage } \\
\hline IIIB & $1(5 \%)$ \\
\hline IV & $18(95 \%)$ \\
\hline \multicolumn{2}{|l|}{ Karnofsky Performance Score } \\
\hline 100 & 0 \\
\hline 90 & $1(5 \%)$ \\
\hline 80 & $19(95 \%)$ \\
\hline \multicolumn{2}{|l|}{ Number of prior lines of therapy } \\
\hline 1 & $9(45 \%)$ \\
\hline 2 & $11(55 \%)$ \\
\hline Prior radiation therapy & $12(60 \%)$ \\
\hline \multicolumn{2}{|l|}{ Histology } \\
\hline Adenocarcinoma & $14(70 \%)$ \\
\hline Squamous cell carcinoma & $5(25 \%)$ \\
\hline Poorly differentiated carcinoma & $1(5 \%)$ \\
\hline \multicolumn{2}{|l|}{ Poststudy treatment } \\
\hline Yes & $17(85 \%)$ \\
\hline No & $3(15 \%)$ \\
\hline
\end{tabular}

line was repressed by more than $75 \%$ as compared to controls, no significant difference was observed among these treatments (data not shown). Carboplatin was chosen to study in combination with ABT-751 because greater than additive antitumor effects with a platinum/ABT-751 combination were observed in a murine cancer model [29].
Individual and combined antineoplastic effects of ABT751 and carboplatin treatments on cancer cell growth were investigated in the human lung cancer cell lines HOP62, A549 and U1571. Subtherapeutic drug concentrations were chosen for study to search for enhancing effects on growth and gene expression in these cell lines after combining ABT-751 with carboplatin. In all of these cell lines, significant growth suppression was observed after combining ABT-751 (200 nM) with carboplatin (5 $\mu \mathrm{M})$ as compared to ABT-751 alone or carboplatin alone (fig. 1). We further studied if this growth suppression was associated with apoptosis induction and expression of cell cycle regulators in HOP62 and A549 cells. The combined treatment significantly increased apoptosis induction as compared to controls for both HOP62 and A549 cells and induced a decline in expression of cell cycle regulators cyclin B1 and cyclin D1 in HOP62 cells, but not in A549 cells (data not shown).

\section{Patient Characteristics}

Between September 2004 and August 2008, 20 patients with advanced NSCLC were enrolled in this trial. The study was administratively closed by the sponsor before it reached full accrual when a larger study of ABT-751 in combination with a different chemotherapy agent, pemetrexed, did not meet its efficacy objectives in previously treated lung cancer. Baseline patient characteristics are presented in table 2 . All patients had prior treatment for their lung cancer, and $80 \%$ had prior platinum-based therapy ( $75 \%$ carboplatin and $5 \%$ cisplatin). The median interval since the prior platinum exposure was 10 months (range 2-26 months). One patient was found to have disease progression in the brain on the day of study enrollment and was not treated with the study regimen. Therefore, 19 patients were evaluable for toxicity and efficacy. 


\section{Safety and Toxicity}

For the phase I portion, 12 patients were enrolled at the dose levels shown in table 1. No DLTs were observed in the patients enrolled at the first 3 dose levels. NonDLTs beyond the first cycle experienced by these patients included grade 2 anemia and grade 2 thrombocytopenia. Treatment was held for 2 weeks for persistent grade 2 thrombocytopenia in 1 patient. At dose level 4, 1 patient experienced DLT of grade 3 fatigue with the first cycle, and had a dose-reduction for carboplatin to the first dosage level for subsequent cycles. Another patient had DLTs of a grade 3 ileus, as well as grade 4 neutropenia requiring hospitalization with the first cycle. A third patient treated at the level 4 dose, had grade 4 pneumonitis, grade 3 hypokalemia and hyponatremia. Given these findings, the MTD was proposed as dose level 3, and the institutional Safety and Data Monitoring Committee recommended that additional patients be enrolled at level 3, prior to completing the phase I portion. None of these patients had DLTs with the first cycle. Non-DLTs that were noted at this level included grade 2 constipation in 2 patients, as well as single reports of grade 2 dysphagia, grade 3 hypokalemia and grade 2 thrombocytopenia. One patient in this group required a dose reduction of carboplatin for grade 2 thrombocytopenia. Another patient had two 1-week delays in treatment: one due to a hospitalization for pneumonia and the other for evaluation of new dyspnea. The MTD was confirmed to be dose level 3 (ABT-751 $125 \mathrm{mg}$ twice daily for 7 days with carboplatin AUC 6) and was chosen as the recommended phase II treatment dose for the expansion portion of the trial. Overall toxicity data are summarized in table 3.

The median number of cycles of ABT-751 administered in the phase I portion was two cycles (range: 1-5) and the overall median number of cycles for the trial was 3 (range: $1-7$ ). For the phase I portion there were 7 treatment delays due to grade 2 thrombocytopenia, hospitalization for non-treatment-related events (neurosurgical procedure and pneumonia), grade 2 fatigue and grade 2 neuropathy. Of the 12 patients who were treated on the phase I portion, 7 discontinued the study drug due to progression of disease. Another patient was advised to come off study after experiencing grade 4 pneumonitis, 1 patient came off the study for worsening performance status and a third patient discontinued treatment for worsening grade 2 neuropathy. Two patients withdrew consent without citing any specific toxicity.

Seven patients were enrolled in the expansion portion of the study at dosage level 3. They received a median of
Table 3. Overall toxicities (19 evaluable patients)

\begin{tabular}{|c|c|c|c|}
\hline Toxicities & $\begin{array}{l}\text { Grade } 1 / 2 \\
\mathrm{n}\end{array}$ & $\begin{array}{l}\text { Grade } 3 \\
\mathrm{n}\end{array}$ & $\begin{array}{l}\text { Grade } 4 \\
\mathrm{n}\end{array}$ \\
\hline \multicolumn{4}{|l|}{ Hematologic } \\
\hline Anemia & $12(63 \%)$ & 0 & 0 \\
\hline Leukopenia & $2(11 \%)$ & 0 & 0 \\
\hline Neutropenia & $5(26 \%)$ & $2(11 \%)$ & $1(5 \%)$ \\
\hline Thrombocytopenia & $9(47 \%)$ & $2(11 \%)$ & $1(5 \%)$ \\
\hline Febrile neutropenia & 0 & 0 & 0 \\
\hline \multicolumn{4}{|l|}{ Nonhematologic } \\
\hline Confusion & $1(5 \%)$ & 0 & 0 \\
\hline Constipation & $10(52 \%)$ & 0 & 0 \\
\hline Dehydration & $1(5 \%)$ & 0 & 0 \\
\hline Dyspepsia & $2(11 \%)$ & 0 & 0 \\
\hline Fatigue & $8(42 \%)$ & $4(21 \%)$ & 0 \\
\hline Hyperlipidemia & $3(16 \%)$ & 0 & 0 \\
\hline Hypokalemia & $4(21 \%)$ & $2(11 \%)$ & 0 \\
\hline Hyponatremia & $9(47 \%)$ & $1(5 \%)$ & 0 \\
\hline Hypophosphatemia & $3(16 \%)$ & 0 & 0 \\
\hline Ileus & $1(5 \%)$ & $1(5 \%)$ & 0 \\
\hline Infection (no neutropenia) & 0 & $2(11 \%)$ & $1(5 \%)$ \\
\hline Myalgia & $1(5 \%)$ & 0 & 0 \\
\hline Nausea/vomiting & $7(37 \%)$ & $1(5 \%)$ & 0 \\
\hline Neurological symptoms & $1(5 \%)$ & $1(5 \%)$ & 0 \\
\hline Neuropathy & $3(16 \%)$ & 0 & 0 \\
\hline Pain & $6(32 \%)$ & $2(11 \%)$ & 0 \\
\hline Pneumonitis & 0 & 0 & $1(5 \%)$ \\
\hline Rash & $1(5 \%)$ & 0 & 0 \\
\hline Transaminase elevation & $1(5 \%)$ & 0 & 0 \\
\hline Weakness & 0 & $2(11 \%)$ & 0 \\
\hline
\end{tabular}

five cycles of treatment (range: $2-7$ ). There were 7 delays in administration of chemotherapy due to grade 2 thrombocytopenia, grade 2 back pain, grade 2 fatigue, grade 2 and 3 neutropenia, grade 2 neuropathy, grade 3 weakness and grade 3 nausea. The dosage of the study drug was reduced in 2 patients. One had grade 2 thrombocytopenia that persisted despite a reduction in the carboplatin dose. The other patient had grade 2 neuropathy. Five patients discontinued the study drug due to disease progression. Two patients completed at least four cycles before stopping without evidence of progression. Overall, after discontinuation of the study drug, 17 subjects (85\%) went on to receive additional therapeutic regimens.

\section{Efficacy}

Two patients (11\%) had partial responses after two cycles: one at dose level 2 and the other at dose level 4 . The durations of responses in these subjects were 14 and 28 
Fig. 2. Relative cyclin D1 expression (normalized to actin as a loading control) in pretreatment (day 0) versus posttreatment buccal swabs (days 4, 8, and 22).

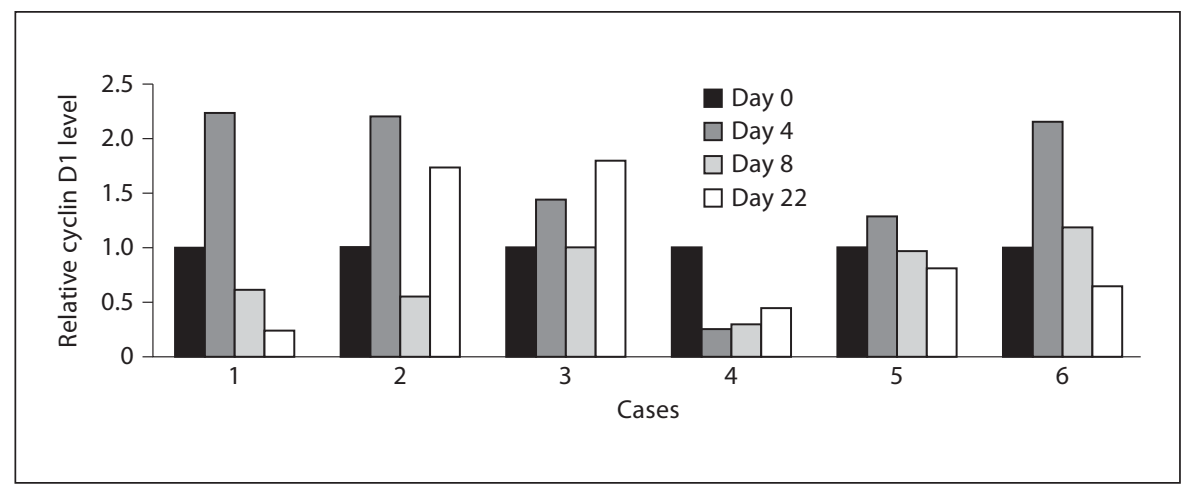

Table 4. Summary of efficacy among patients on level 3 dosages

\begin{tabular}{ll}
\hline Endpoint & \\
\hline Response at two cycles (RECIST criteria) & \\
$\quad$ Complete response & 0 \\
$\quad$ Partial response & 0 \\
$\quad$ Stable disease & $7(64 \%)$ \\
$\quad$ Progressive disease & $4(36 \%)$ \\
Time to progression & \\
$\quad$ Median, months & 2.8 \\
95\% CI, months & $2.0-3.7$ \\
Overall survival & \\
$\quad$ Median, months & 11.7 \\
95\% CI, months & $5.9-27.0$ \\
Progression-free survival & \\
$\quad$ Median, months & 2.83 \\
95\% CI, months & $1.3-5.2$ \\
\hline
\end{tabular}

weeks, respectively. Both subjects had received prior platinum-containing regimens, one with cisplatin and progression of disease as best response, 19 months prior to study enrollment, and one with carboplatin and partial response as best response, 11 months prior to enrollment. There was no association between the interval from or the response to prior platinum treatment and the outcome from the study treatment. All 3 patients who had not had prior platinum agent exposure achieved stable disease as best response to the study combination. Efficacy endpoints for the 11 patients treated at the recommended phase II dose are summarized in table 4 . Seven patients had stable disease and 4 patients progressed. The median time to tumor progression was 2.8 months $(95 \%$ CI 2.0-2.7). The median overall survival was 11.7 months (95\% CI 5.9-27.0). The median survival was 2.8 months (95\% CI 1.3-5.2).
Pharmacodynamic Analysis of Cyclin D1 in Buccal Swabs

Cyclin D1 levels were evaluated by immunoblot analyses of pretreatment (day 0) and paired posttreatment (day 4,8 and 22) buccal swabs. Relative cyclin D1 levels were obtained by normalizing cyclin D1 levels to actin levels. Six paired buccal swab samples were obtained from patients treated at the phase II dosage. All of these patients had stable disease after treatment with the study regimen. Out of these 6 paired buccal swabs, 3 showed decline in cyclin D1 expression on day 8 , and 4 showed a decline on day 22, relative to baseline cyclin D1 levels (fig. 2). There was not enough protein in the samples for analysis of cyclin B1 expression.

\section{Discussion}

Treatment of advanced NSCLC is a major challenge in oncology. While increasing attention to personalized therapy based on individual tumor and patient characteristics holds great promise, treatment outcomes with current agents need to be improved. This phase I trial combined a well-established agent in the treatment of advanced lung cancer, carboplatin, with a novel antimicrotubule agent, ABT-751, which was shown in preclinical studies to be active against lung cancer cells and xenograft tumors [29]. ABT-751 is reported as less susceptible to drug resistance mechanisms described for other antimicrotubule agents $[17,22]$. We studied a twice-daily dosing schedule for 1 week of a 3-week cycle and this trial established an MTD and recommended phase II dose of ABT-751 $125 \mathrm{mg}$ twice a day with carboplatin at an AUC of 6 . The drug combination was safe and well tolerated. The DLTs were ileus, fatigue and neutropenia. Two patients (11\%) had confirmed partial response after two 
cycles. The median survival was 11.7 months (95\% CI 5.9-27.0) and the time to tumor progression was 2.8 months (95\% CI 2.0-2.7).

In the phase I clinical trial, the most common side effects were constipation (grade $1 / 2$ in $52 \%$ of patients), thrombocytopenia ( $47 \%$ grade $1 / 2$ and $11 \%$ grade 3 ), anemia $(63 \%$, all grade $1 / 2)$, nausea ( $37 \%$ grade $1 / 2,5 \%$ grade 3 ) and fatigue ( $42 \%$ grade $1 / 2$ and $5 \%$ grade 3 ). Overall, this toxicity profile for ABT-751 was consistent with other trials of this agent, with gastrointestinal side effects as the most prominent side effect observed [40, 41]. Previous trials of single agent ABT-751 were notable for the lack of myelosuppression [23-25, 40]. While there are few single-agent carboplatin trials in lung cancer for direct comparison, the rates of myelosuppression in our trial are similar to published results [42]. This suggests that myelosuppression was likely from carboplatin and the addition of ABT-751 did not enhance this appreciably. This is in contrast to other current therapies for advanced NSCLC. For example, the combination of paclitaxel, carboplatin and bevacizumab was notable for a relatively high degree of myelosuppression (25\% grade 4 neutropenia) and bleeding events, but not for gastrointestinal toxicity [43]. Thus, the toxicity profile reported here does appear distinct and makes ABT751 a potential agent for combination therapies, especially with those which cause myelosuppression as their adverse effects.

The combination of ABT-751 and carboplatin demonstrated modest activity against NSCLC with 2 patients out of 19 (11\%) achieving a confirmed partial response after two cycles. As the majority of the study patients had received prior carboplatin, this activity likely reflects the benefits of the combination, although a benefit from the rechallenge with carboplatin could not be excluded, given the relatively long interval from the prior platinum exposure. This is similar to the $8 \%$ response rate seen with the currently approved therapies beyond first line. After the initiation of our combination study, two multicenter trials of ABT-751 with docetaxel or pemetrexed compared to chemotherapy alone in the second-line setting were opened. A different schedule of ABT-751 given once daily for 14 days was chosen based on more recent data. The ABT-751/docetaxel trial was terminated early due to excess toxicities. The ABT-751/pemetrexed trial did not establish effectiveness in treating unselected NSCLC patients but showed a trend of improved outcome for the squamous NSCLC subpopulation [41]. We could not identify any specific subset of patients with NSCLC to derive differential benefit from treatment with our drug combination. We noticed that the twicedaily schedule used in our clinical trial was difficult for some patients to comply with, although it was tolerated. Yet, the once-daily schedule of ABT-751 was well tolerated [41]. Therefore, if future studies of ABT-751 with carboplatin in lung cancer are conducted, alternative schedules, such as once-daily dosing, should be considered. Moreover, since most patients in our study had been previously treated with carboplatin, inclusion of chemotherapy-naïve patients and excluding previous carboplatin treatment will allow a more precise assessment of the efficacy of the combination in this different study population.

In a search for biomarkers that would predict responses to ABT-751 and carboplatin combination treatment, we evaluated expression of cyclins since both ABT-751 and carboplatin induce cell cycle arrest. In our in vitro studies, combining ABT-751 with carboplatin significantly decreased human lung cancer cell growth and significantly induced apoptosis. This drug combination led to a substantial cyclin D1 repression and a trend towards cyclin B1 suppression in HOP62 cells. A549 cells did not show suppression of cyclin B1 or cyclin D1 expression after these drug treatments, suggesting that the association of growth inhibition with suppression of these cyclins may be cell context dependent at the dosage examined and that other mechanisms including apoptosis induction may play a greater role in reducing tumor cell proliferation. In addition, since subtherapeutic dosages were used to explore cooperation between these two drugs, it is possible that cyclins would be repressed upon drug treatments at higher dosages. In our clinical study, we evaluated cyclin D1 levels in 6 paired pretreatment versus posttreatment buccal swabs. Four of these 6 specimens showed a decrease in cyclin D1 protein expression on day 22 after treatment as compared to the pretreatment swabs. To evaluate whether cyclin D1 was a clinically relevant biomarker for this drug regimen, we compared these decreased cyclin D1 levels to the observed clinical responses. All of these 6 patients had stable disease independent of the changes in cyclin D1 levels. Based on these findings, cyclin D1 may not serve as a clinically predictive biomarker of antitumor response in this trial population. Further investigations are needed to explore other candidate biomarkers, such as circulating tumor cells, squamous cell carcinoma antigen and cytokeratin 19 fragment antigen 21-1 that were highlighted in other ABT-751 clinical trials $[27,41]$. 
In conclusion, the combination of ABT-751 and carboplatin markedly suppressed lung cancer cell growth in vitro, and had modest antitumor activity in advanced NSCLC patients previously treated with carboplatin. Our findings suggest that additional investigation of this combination in lung cancer is not recommended. ABT-751 is clinically well tolerated and further studies in different patient populations, such as chemotherapynaïve lung cancer patients, in alternative schedules, in other tumor types, and in combination with other therapies may be pursued only after a successful search for biomarkers that reliably predict clinical responses to ABT-751 treatment and its combination with other therapies.

\section{Acknowledgments}

This work was supported by a Commonwealth Foundation award (K.H.D. and E.D.), National Institutes of Health (NIH) and National Cancer Institute (NCI) grants R01 CA087546 (E.D.), R01 CA111422 (E.D.), a Samuel Waxman Cancer Research Foundation award (E.D.), and by an American Cancer Society Clinical Research Professorship (E.D.) supported by a generous gift from the FM Kirby Foundation.

ClinicalTrials.gov identifier: NCT00735878.

\section{Disclosure Statement}

A.E.H. and G.B.G. are employees of Abbott Laboratories. K.H.D. received research funding from Abbott Laboratories. The other authors declare no conflicts of interest.

\section{References}

1 Garcia M, Jemal A, Ward EM, Center MM, Hao Y, Siegel RL, Thun MJ: Global Cancer Facts \& Figures 2007. Atlanta, American Cancer Society, 2007.

-2 Pfister DG, Johnson DH, Azzoli CG, Sause W, Smith TJ, Baker S Jr, Olak J, Stover D, Strawn JR, Turrisi AT, Somerfield MR: American Society of Clinical Oncology Treatment of unresectable non-small-cell lung cancer guideline: update 2003. J Clin Oncol 2004;22:330-353.

-3 Socinski MA, Crowell R, Hensing TE, Langer CJ, Lilenbaum R, Sandler AB, Morris D: American College of Chest Physicians Treatment of non-small cell lung cancer, stage IV: ACCP evidence-based clinical practice guidelines (2nd edition). Chest 2007;132: 277S-289S

4 National Comprehensive Cancer Network. The NCCN Clinical Practice Guidelines in Oncology: Non-Small Cell Lung Cancer (v. 2.2013). Fort Washington, National Comprehensive Cancer Network, 2012.

5 Komuta K, Osaki T, Mori M, Yokota S, Tanio Y, Matsui K, Imamura F, Kawase I: A phase II study directed by a clinical pathway for carboplatin and weekly paclitaxel in previously untreated patients with unresectable non-small cell lung cancer. Chemotherapy 2010;56:39-45.

-6 Azzoli CG, Baker S Jr, Temin S, Pao W, Aliff T, Brahmer J, Johnson DH, Laskin JL, Masters G, Milton D, Nordquist L, Pfister DG, Piantadosi S, Schiller JH, Smith R, Smith TJ, Strawn JR, Trent D, Giaccone G: American Society of Clinical Oncology Clinical Practice Guideline update on chemotherapy for stage IV non-small cell lung cancer. J Clin Oncol 2009;27:6251-6266.
7 Imamura F, Nishio M, Noro R, Tsuboi M, Ikeda N, Inoue A, Ohsaki Y, Kimura Y, Nishino K, Uchida J, Horai T: Randomized phase II study of two schedules of carboplatin and gemcitabine for stage IIIB and IV advanced non-small cell lung cancer (JACCRO LC-01 study). Chemotherapy 2011;57:357362.

8 Fossella F, Pereira JR, von Pawel J, Pluzanska A, Gorbounova V, Kaukel E, Mattson KV, Ramlau R, Szczesna A, Fidias P, Millward M, Belani CP: Randomized, multinational, phase III study of docetaxel plus platinum combinations versus vinorelbine plus cisplatin for advanced non-small-cell lung cancer: the TAX 326 study group. J Clin Oncol 2003; 21:3016-3024.

-9 Huisman C, Smit EF, Giaccone G, Postmus PE: Second-line chemotherapy in relapsing or refractory non-small-cell lung cancer: a review. J Clin Oncol 2000;18:3722-3730.

10 Shepherd FA, Dancey J, Ramlau R, Mattson K, Gralla R, O’Rourke M, Levitan N, Gressot L, Vincent M, Burkes R, Coughlin S, Kim Y, Berille J: Prospective randomized trial of docetaxel versus best supportive care in patients with non-small-cell lung cancer previously treated with platinum-based chemotherapy. J Clin Oncol 2000;18:2095-2103.

$\checkmark 11$ Hanna N, Shepherd FA, Fossella FV, Pereira JR, De Marinis F, von Pawel J, Gatzemeier U, Tsao TC, Pless M, Muller T, Lim HL, Desch C, Szondy K, Gervais R, Shaharyar, Manegold C, Paul S, Paoletti P, Einhorn L, Bunn PA Jr: Randomized phase III trial of pemetrexed versus docetaxel in patients with nonsmall-cell lung cancer previously treated with chemotherapy. J Clin Oncol 2004;22: 1589-1597.
12 Shepherd FA, Rodrigues Pereira J, Ciuleanu T, Tan EH, Hirsh V, Thongprasert S, Campos D, Maoleekoonpiroj S, Smylie M, Martins R, van Kooten M, Dediu M, Findlay B, Tu D, Johnston D, Bezjak A, Clark G, Santabárbara P, Seymour L: Erlotinib in previously treated non-small-cell lung cancer. N Engl J Med 2005;353:123-132.

13 Kim ES, Hirsh V, Mok T, Socinski MA, Gervais $R, W u$ YL, Li LY, Watkins CL, Sellers MV, Lowe ES, Sun Y, Liao ML, Osterlind K, Reck M, Armour AA, Shepherd FA, Lippman SM, Douillard JY: Gefitinib versus docetaxel in previously treated non-small-cell lung cancer (INTEREST): a randomised phase III trial. Lancet 2008;372:1809-1818.

14 Chung FT, Lee KY, Fang YF, Shieh MH, Lin SM, Yu CT, Lo YL, Lin TY, Kuo CH, Feng PH, Ni YL, Kuo HP: Low-dose weekly docetaxel is as tolerable as pemetrexed in previously treated advanced non-small-cell lung cancer. Chemotherapy 2011;57:147-155.

15 Lee J, Harris L: Antimicrotubule agents; in DeVita VT Jr, Lawrence TSR, Rosenberg SA (eds): Devita, Hellman and Rosenberg's Cancer: Principles and Practice of Oncology. Philadelphia, Lippincott, Williams \& Wilkins, 2008, pp 447-456.

$\checkmark 16$ Yoshino H, Ueda N, Niijima J, Sugumi H, Kotake Y, Koyanagi N, Yoshimatsu K, Asada M, Watanabe T, Nagasu T, Tsukahara K, Iijima A, Kitoh K: Novel sulfonamides as potential, systemically active antitumor agents. J Med Chem 1992;35:2496-2497.

17 Yoshimatsu K, Yamaguchi A, Yoshino H, Koyanagi N, Kitoh K: Mechanism of action of E7010, an orally active sulfonamide antitumor agent: inhibition of mitosis by binding to the colchicine site of tubulin. Cancer Res 1997;57:3208-3213. 
-18 Segreti JA, Polakowski JS, Koch KA, Marsh KC, Bauch JL, Rosenberg SH, Sham HL, Cox BF, Reinhart GA: Tumor selective antivascular effects of the novel antimitotic compound ABT-751: an in vivo rat regional hemodynamic study. Cancer Chemother Pharmacol 2004;54:273-281.

- 19 Luo Y, Hradil VP, Frost DJ, Rosenberg SH, Gordon GB, Morgan SJ, Gagne GD, Cox BF, Tahir SK, Fox GB: ABT-751, a novel tubulinbinding agent, decreases tumor perfusion and disrupts tumor vasculature. Anticancer Drugs 2009;20:483-492.

-20 Koyanagi N, Nagasu T, Fujita F, Watanabe T, Tsukahara K, Funahashi Y, Fujita M, Taguchi $\mathrm{T}$, Yoshino $\mathrm{H}$, Kitoh $\mathrm{K}$ : In vivo tumor growth inhibition produced by a novel sulfonamide, E7010, against rodent and human tumors. Cancer Res 1994;54:1702-1706.

-21 Morton CL, Favours EG, Mercer KS, Boltz CR, Crumpton JC, Tucker C, Billups CA, Houghton PJ: Evaluation of ABT-751 against childhood cancer models in vivo. Invest New Drugs 2007;25:285-295.

-22 Galmarini CM: ABT-751 (Abbott). Curr Opin Investig Drugs 2005;6:623-630.

-23 Fox E, Maris JM, Widemann BC, Meek K, Goodwin A, Goodspeed W, Kromplewski M, Fouts ME, Medina D, Cho SY, Cohn SL, Krivoshik A, Hagey AE, Adamson PC, Balis FM: A phase 1 study of ABT-751, an orally bioavailable tubulin inhibitor, administered daily for 7 days every 21 days in pediatric patients with solid tumors. Clin Cancer Res 2006; 12:4882-4887.

-24 Fox E, Maris JM, Widemann BC, Goodspeed W, Goodwin A, Kromplewski M, Fouts ME, Medina D, Cohn SL, Krivoshik A, Hagey AE, Adamson PC, Balis FM: A phase I study of ABT-751, an orally bioavailable tubulin inhibitor, administered daily for 21 days every 28 days in pediatric patients with solid tumors. Clin Cancer Res 2008;14:1111-1115.

$\checkmark 25$ Hande KR, Hagey A, Berlin J, Cai Y, Meek K, Kobayashi H, Lockhart AC, Medina D, Sosman J, Gordon GB, Rothenberg ML: The pharmacokinetics and safety of ABT-751, a novel, orally bioavailable sulfonamide antimitotic agent: results of a phase 1 study. Clin Cancer Res 2006;12:2834-2840.

-26 Yamamoto K, Noda K, Yoshimura A, Fukuoka M, Furuse K, Niitani H: Phase I study of E7010. Cancer Chemother Pharmacol 1998; 42:127-134.
27 Yee KW, Hagey A, Verstovsek S, Cortes J, Garcia-Manero G, O'Brien SM, Faderl S, Thomas D, Wierda W, Kornblau S, Ferrajoli A, Albitar M, McKeegan E, Grimm DR, Mueller T, Holley-Shanks RR, Sahelijo L, Gordon GB, Kantarjian HM, Giles FJ: Phase 1 study of ABT-751, a novel microtubule inhibitor, in patients with refractory hematologic malignancies. Clin Cancer Res 2005;11: 6615-6624.

28 Michels J, Ellard SL, Le L, Kollmannsberger C, Murray N, Tomlinson Guns ES, Carr R, Chi KN: A phase IB study of ABT-751 in combination with docetaxel in patients with advanced castration-resistant prostate cancer. Ann Oncol 2010;21:305-311.

29 Jorgensen TJ, Tian H, Joseph IB, Menon K, Frost D: Chemosensitization and radiosensitization of human lung and colon cancers by antimitotic agent, ABT-751, in athymic murine xenograft models of subcutaneous tumor growth. Cancer Chemother Pharmacol 2007;59:725-732.

30 Rosell R, Gatzemeier U, Betticher DC, Keppler U, Macha HN, Pirker R, Berthet P, Breau JL, Lianes P, Nicholson M, Ardizzoni A, Chemaissani A, Bogaerts J, Gallant G: Phase III randomised trial comparing paclitaxel/carboplatin with paclitaxel/cisplatin in patients with advanced non-small-cell lung cancer: a cooperative multinational trial. Ann Oncol 2002;13:1539-1549.

31 Zatloukal P, Petruzelka L, Zemanová M, Kolek V, Skricková J, Pesek M, Fojtů $\mathrm{H}$ Grygárková I, Sixtová D, Roubec J, Horenková E, Havel L, Průsa P, Nováková L, Skácel T, Kůta M: Gemcitabine plus cisplatin vs gemcitabine plus carboplatin in stage IIIb and IV non-small cell lung cancer: a phase III randomized trial. Lung Cancer 2003;41:321-331.

32 Petty WJ, Dragnev KH, Memoli V, Ma Y, De sai NB, Biddle A, Davis TH, Nugent WC, Memoli N, Hamilton M, Iwata KK, Rigas JR, Dmitrovsky E: Epidermal growth factor receptor tyrosine kinase inhibition represses cyclin D1 in aerodigestive tract cancers. Clin Cancer Res 2004;10:7547-7554.

33 Dragnev KH, Ma T, Cyrus J, Galimberti F, Memoli V, Busch AM, Tsongalis GJ, Seltzer M, Johnstone D, Erkmen CP, Nugent W, Rigas JR, Liu X, Freemantle SJ, Kurie JM, Waxman S, Dmitrovsky E: Bexarotene plus erlotinib suppress lung carcinogenesis independent of KRAS mutations in two clinical trials and transgenic models. Cancer Prev Res 2011;4:818-828.

>34 Simon R, Freidlin B, Rubinstein L, Arbuck SG, Collins J, Christian MC: Accelerated titration designs for phase I clinical trials in oncology. J Natl Cancer Inst 1997;89:1138-1147.
35 Cancer Therapy Evaluation Program: Common Terminology Criteria for Adverse Events (v3.0). Bethesda, National Cancer Institute, 2003

36 Therasse P, Arbuck SG, Eisenhauer EA, Wanders J, Kaplan RS, Rubinstein L, Verweij J, Van Glabbeke M, van Oosterom AT, Christian MC, Gwyther SG: New guidelines to evaluate the response to treatment in solid tumors. European Organization for $\mathrm{Re}$ search and Treatment of Cancer, National Cancer Institute of the United States, National Cancer Institute of Canada. J Natl Cancer Inst 2000;92:205-216.

37 Hande KR, Wolff SN, Greco FA, Hainsworth JD, Reed G, Johnson DH: Etoposide kinetics in patients with obstructive jaundice. J Clin Oncol 1990;8:1101-1107.

>38 Maurel J, Zorrilla M, Puertolas T, Anton A, Herrero A, Artal A, Alonso V, MartinezTrufero J, Puertas MM: Phase I trial of weekly gemcitabine at 3-h infusion in refractory, heavily pretreated advanced solid tumors. Anticancer Drugs 2001;12:713-717.

39 Oguri S, Sakakibara T, Mase H, Shimizu T, Ishikawa K, Kimura K, Smyth RD: Clinical pharmacokinetics of carboplatin. J Clin Pharmacol 1988;28:208-215.

40 Mauer AM, Cohen EE, Ma PC, Kozloff MF, Schwartzberg L, Coates AI, Qian J, Hagey AE, Gordon GB: A phase II study of ABT-751 in patients with advanced non-small cell lung cancer. J Thorac Oncol 2008;3:631-636.

-41 Rudin CM, Mauer A, Smakal M, Juergens R, Spelda S, Wertheim M, Coates A, McKeegan E, Ansell P, Zhou X, Qian J, Pradhan R, Dowell B, Krivoshik A, Gordon G: Phase I/II study of pemetrexed with or without ABT751 in advanced or metastatic non-small-cell lung cancer. J Clin Oncol 2011;29:1075-1082.

42 White SC, Lorigan P, Middleton MR, Anderson H, Valle J, Summers Y, Burt PA, Arance A, Stout R, Thatcher N: Randomized phase II study of cyclophosphamide, doxorubicin, and vincristine compared with single-agent carboplatin in patients with poor prognosis small cell lung carcinoma. Cancer 2001;92: 601-608.

43 Sandler A, Gray R, Perry MC, Brahmer J, Schiller JH, Dowlati A, Lilenbaum R, Johnson DH: Paclitaxel-carboplatin alone or with bevacizumab for non-small-cell lung cancer. N Engl J Med 2006;355:2542-2550. 